\title{
Multicenter Postmarket Analysis of the Neuroform Atlas Stent for Stent-Assisted Coil Embolization of Intracranial Aneurysms
}

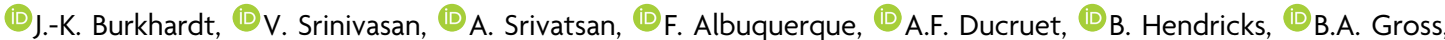

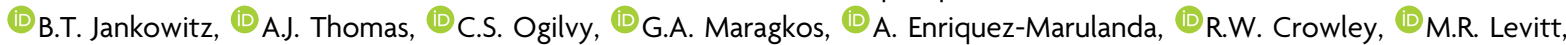

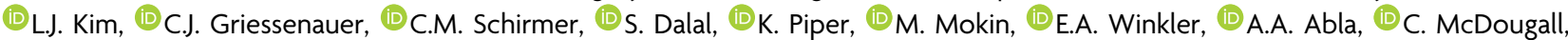

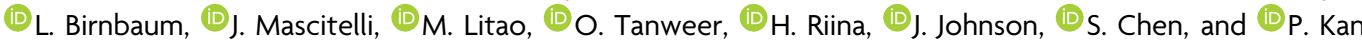

\section{ABSTRACT}

BACKGROUND AND PURPOSE: The Neuroform Atlas is a new microstent to assist coil embolization of intracranial aneurysms that recently gained FDA approval. We present a postmarket multicenter analysis of the Neuroform Atlas stent.

MATERIALS AND METHODS: On the basis of retrospective chart review from 11 academic centers, we analyzed patients treated with the Neuroform Atlas after FDA exemption from January 2018 to June 2019. Clinical and radiologic parameters included patient demographics, aneurysm characteristics, stent parameters, complications, and outcomes at discharge and last follow-up.

RESULTS: Overall, 128 aneurysms in 128 patients (median age, 62 years) were treated with 138 stents. Risk factors included smoking (59.4\%), multiple aneurysms (27.3\%), and family history of aneurysms (16.4\%). Most patients were treated electively (93.7\%), and 8 (6.3\%) underwent treatment within 2 weeks of subarachnoid hemorrhage. Previous aneurysm treatment failure was present in $21 \%$ of cases. Wide-neck aneurysms (80.5\%), small aneurysm size ( $<7 \mathrm{~mm}, 76.6 \%)$, and bifurcation aneurysm location (basilar apex, 28.9\%; anterior communicating artery, $27.3 \%$; and middle cerebral artery bifurcation, $12.5 \%$ ) were common. A single stent was used in $92.2 \%$ of cases, and a single catheter for both stent placement and coiling was used in $59.4 \%$ of cases. Technical complications during stent deployment occurred in $4.7 \%$ of cases; symptomatic thromboembolic stroke, in $2.3 \%$; and symptomatic hemorrhage, in $0.8 \%$. Favorable Raymond grades (Raymond-Roy occlusion classification) I and II were achieved in $82.9 \%$ at discharge and $89.5 \%$ at last follow-up. mRS $\leq 2$ was determined in $96.9 \%$ of patients at last follow-up. The immediate Raymond-Roy occlusion classification grade correlated with aneurysm location $(P<.0001)$ and rupture status during treatment $(P=.03)$.

CONCLUSIONS: This multicenter analysis provides a real-world safety and efficacy profile for the treatment of intracranial aneurysms with the Neuroform Atlas stent.

ABBREVIATIONS: AcomA = anterior communicating artery; RROC = Raymond-Roy occlusion classification

$\mathbf{T}$ he recently FDA-approved Neuroform Atlas (Stryker) stent is a new microstent to assist coil embolization of intracranial aneurysms. Gaining CE marking in Europe in May 2015, this

Received February 13, 2020; accepted after revision March 29.

From the Department of Neurosurgery (J.-K.B., V.S., A.S., O.T., J.J., S.C., P.K.), Baylor College of Medicine, Houston, Texas; Department of Neurosurgery (F.A., A.F.D., B.H.), Barrow Neurological Institute, Phoenix, Arizona; Department of Neurological Surgery (B.A.G.), University of Pittsburgh Medical Center Presbyterian, Pittsburgh, Pennsylvania; Department of Neurosurgery (B.T.J.), Cooper University, Camden, New Jersey; Beth Israel Deaconess Medical Center (A.J.T., C.S.O., G.A.M.), Harvard Medical School, Boston, Massachusetts; Boston Medical Center (A.E.-M.), Boston, Massachusetts; Department of Neurosurgery (R.W.C.), Rush Medical College, Chicago, Illinois; Department of Neurological Surgery (M.R.L., L.J.K.), University of Washington, Seattle, Washington; Department of Neurosurgery (C.J.G., C.M.S., S.D.), Geisinger Health, Danville, Pennsylvania; Research Institute of Neurointervention (C.J.G., C.M.S.), Paracelsus Medical University, Salzburg, Austria; Department of Neurosurgery (K.P., M.M.), University of Southern Florida College of Public Health, Tampa, Florida; Department of Neurological Surgery (E.A.W., A.A.A.), University of California, San Francisco, San Francisco, California; device was just recently approved in the United States (Humanitarian Device Exemption approval in January 2018 and premarket approval in May 2019). Therefore, large clinical experience with this device and published case series are not available in the literature.

Department of Neurosurgery (C.M., L.B., J.M.), University of Texas Health San Antonio, San Antonio, Texas; and Department of Neurosurgery (M.L., O.T., H.R.) NYU Langone Medical Center, New York, New York.

Paper previously presented at: Congress of Neurological Surgeons, July 30, 2019; Schaumburg, Illinois.

Please address correspondence to Jan-Karl Burkhardt, MD, Department of Neurosurgery, Baylor College of Medicine Medical Center, 7200 Cambridge St, Suite 9B, Houston, TX 77030; e-mail: Jan-Karl.Burkhardt@bcm.edu; (janKarlBurkharl

Indicates article with supplemental on-line tables.

http://dx.doi.org/10.3174/ajnr.A6581 
Meant to treat wide-neck aneurysms and aneurysms located at vessel bifurcations in the anterior circulation, the Atlas stent aims to further improve aneurysm coiling through its application in smalldiameter parent vessels. The exact approved FDA indications include the use of the Neuroform Atlas stent with neurovascular embolization coils in the anterior circulation of the neurovasculature for the endovascular treatment of patients 18 years of age or older with saccular wide-neck (neck width $\geq 4 \mathrm{~mm}$ or a dome-toneck ratio of $<2$ ) intracranial aneurysms arising from a parent vessel with diameters of $\geq 2.0$ and $\leq 4.5 \mathrm{~mm}$. Therefore, posterior circulation aneurysms are "off-label." The Atlas stent can be delivered through a standard coiling $(0.017$-inch) catheter, thus making the procedure simpler and possibly safer than earlier-generation stents. The same microcatheter can deploy the Atlas stent in the parent vessel and then be navigated through the stent struts into the aneurysm for coiling (re-probing or re-crossing). Another option is to leave 1 microcatheter in the aneurysm for eventual coiling and deploy the stent with a second microcatheter (jailing technique). This technique is usually not needed with the Atlas device but may be required on the basis of aneurysm and parent vessel anatomy. It can also be used as a rescue stent procedure by deploying a stent after coiling is initiated and the coils are extruded.

Previous studies have demonstrated that stent-assisted coiling with this device is feasible and safe for the patient in a clinical trial setting, ${ }^{1-4}$ but a postmarket analysis from daily clinical practice is not available in the literature. The aim of this study was to analyze the efficacy and safety of the device in the postmarket approval period in the United States.

\section{MATERIALS AND METHODS}

Study Design, Participating Centers, and Inclusion Criteria This multicenter retrospective cohort study included all consecutive patients of the participating centers with intracranial aneurysms treated with the Neuroform Atlas stent after the FDA Humanitarian Device Exemption approval from January 2018 until June 2019. The following US academic neurosurgical centers participated in this study: Baylor College of Medicine Medical Center $(n=10)$, New York University Langone Medical Center $(n=13)$, Geisinger Medical Center $(n=7)$, Beth Israel Medical Center $(n=20)$, University of Southern Florida $(n=11)$, University of Texas San Antonio $(n=12)$, University of California, San Francisco $(n=8)$, University of Pittsburgh Medical Center $(n=15)$, University of Washington Seattle $(n=4)$, Rush University Chicago $(n=3)$, and Barrow Neurological Institute $(n=25)$.

Aneurysms were included in this study if they had wide-neck characteristics or because the operator thought that it was appropriate to use the Atlas stent. Posterior circulation aneurysms were included in this study as well, though they were treated as off-label.

The study was approved by the local institutional review board at each participating center for retrospective data collection and review after approval at Baylor College of Medicine, serving as the primary site for de-identified data analysis. The following information was then collected at each center and sent to Baylor College of Medicine without patient identification for analysis: patient demographics, aneurysm and parent vessel characteristics, antiplatelet regimen and platelet function test results if obtained, and procedural details on the Atlas stent. Data on complications as well as patient outcomes were collected on the basis of angiographic data for radiologic outcome, mRS score, symptoms details, and NIHSS for clinical outcome immediately after the procedure and at last follow-up as available.

\section{Neuroform Atlas Stent and Procedure Details}

The self-expanding nitinol Neuroform Atlas stent is characterized by its mixed open-cell and closed-cell design, and cell size has been reduced compared with the previous generation of the Neuroform stents. The stent is available in diameters between 3 and $4.5 \mathrm{~mm}$ with lengths of $15,21,24$, and $30 \mathrm{~mm}$; has 3 radiopaque markers; and can be deployed through a 0.017 -inch microcatheter such as an Excelsior SL-10 (Stryker). ${ }^{1}$

The procedure itself, including dose and type of antiplatelet management, was under the discretion of the participating neurointerventionalist with the choice of a jailed or re-probed technique. The choice of coils was left to the discretion of the treating neurointerventionalist. Antiplatelet management was also left to the discretion of the treating neurointerventionalist and mainly consisted of dual-antiplatelet medication with aspirin and clopidogrel or ticagrelor at least 5 days before and up to 3 months after the procedure with continuation of aspirin monotherapy after 3 months.

\section{Radiographic and Clinical Outcome}

Radiographic outcome was measured using DSA or MRA according to institution-specific follow-up protocol. The degree of aneurysm treatment success was assessed according to the revised Raymond-Roy occlusion classification (RROC) immediately after the procedure and at last follow-up by each center. ${ }^{5}$ Clinical outcome was measured with the mRS before and immediately after the procedure and at last follow-up by each center. In patients with $\mathrm{SAH}$, the Hunt and Hess grade and Fisher scales were used to grade the severity of the SAH.

Clinical and radiologic complications were defined as any deviation from expectation during or after the procedure.

\section{Literature Review and Statistical Analysis}

All available clinical case series that used Atlas stent-assisted coiling were searched on PubMed, and the data provided were compared with our results. Data were presented as a median with interquartile range for continuous variables and proportions for categoric variables. The Pearson $\chi^{2}$ test and ANOVA were used to assess differences between groups for categoric and continuous variables, respectively. Significance was assessed at $P<.05$. All analyses were performed using the Statistical Package for the Social Sciences, Version 24 (IBM).

\section{RESULTS}

\section{Patient Characteristics}

Overall, 128 patients were treated with Atlas stent-assisted coiling for 128 aneurysms in 11 academic neurovascular centers (On-line Table 1). Female sex was more common in this cohort $(71.1 \%$, $n=91$ ), with an overall median age of 62 years (range, 16-84 years). Multiple aneurysms were present in $27.3 \%(n=35)$ of the cases, with a family history for aneurysms found in $16.4 \%(n=21)$. Smoking as a risk factor was present in 76 patients, including active 
smokers $(n=69,53.9 \%)$ and former smokers $(n=7,5.5 \%)$. Most of the treated aneurysms presented as unruptured $(86.7 \%, n=111)$, but 9 patients $(7 \%)$ had an SAH $>2$ weeks, and 8 patients $(6.3 \%)$, $<2$ weeks before treatment.

\section{Aneurysm Characteristics}

Most treated aneurysms were $<7 \mathrm{~mm}(n=98,76.6 \%)$, with a median neck size of $3.9 \mathrm{~mm}$ (range, $2-14 \mathrm{~mm}$ ) and a median dome-toneck ratio of $1.6(0.6-5)$ (On-line Table 1). Wide-neck aneurysms were present in $80.5 \%(n=103)$ and $49.2 \%(n=63)$ based on a dome-to-neck ratio of $<2$ and an aneurysm neck size of $>4 \mathrm{~mm}$, respectively. The most common aneurysm locations were the apex of the basilar artery $(n=37,28.9 \%)$, followed by the anterior communicating artery (AcomA) $(n=35,27.3 \%)$ and the MCA $(n=19$, $14.8 \%$ ) (On-line Table 1$)$. In $76.6 \%$ of cases $(n=98)$, the decision for Atlas stent-assisted coiling was made by the treating neurointerventionalist due to a large aneurysm neck. In $21 \%(n=27)$ of the cases, the decision was made on the basis of a failed previous treatment, including both open microsurgical clipping $(n=4)$ and endovascular coiling $(n=23)$.

\section{Procedure Details}

In most the cases, only 1 Atlas stent was used to treat the aneurysm $(92.2 \%, n=118)$. A single catheter for stent deployment followed by re-probing the stent for coiling was used in $59.4 \%$ $(n=76)$ of cases (On-line Table 1$)$. The most common stent size used in this cohort was $3 \mathrm{~mm}$, including $3 \times 21 \mathrm{~mm}(25 \%$, $n=32), 3 \times 24(25.9 \%, n=33)$, and $3 \times 15 \mathrm{~mm}(18 \%, n=23)$. Most patients were tested for platelet function before the procedure (P2Y12 testing in 67.2\%, $n=86$ ), and the most common combination of periprocedural antiplatelet drug regimen was aspirin, $325 \mathrm{mg}$, plus clopidogrel, $75 \mathrm{mg}$, daily 5-7 days before the procedure $(83.6 \%, n=107)$ (On-line Table 1). A small subset of patients had a vessel diameter of $<1.5 \mathrm{~mm}$ (23 of 128 patients, $18 \%$ ), and stent-assisted coiling was still feasible in this subset of patients.

\section{Complications}

Technical complications occurred in 6 cases (4.7\%), including stent-deployment failure $(n=3)$, failure of re-probing to coil the aneurysm after stent deployment requiring placement of a flow diverter over the Atlas stent $(n=1)$, stent migration after deployment $(n=1)$, and coil protrusion through stent struts $(n=1)$. Thromboembolic complications were observed in 6 cases $(4.7 \%)$ during the procedure and were treated with intra-arterial thrombolysis. Three of the 6 cases were asymptomatic after the procedure $(n=3 / 128,2.3 \%)$. All 6 patients were on aspirin, $325 \mathrm{mg}$, and clopidogrel, $75 \mathrm{mg}$, daily before the procedure, and the P2Y12 showed clopidogrel response in all patients. All patients received an intra-arterial glycoprotein IIb/IIIa inhibitor in addition to heparin during thrombosis. One patient also received intra-arterial tPA. Hemorrhagic complications occurred in 2 patients $(1.6 \%)$, including one during the procedure and the second during postoperative follow-up. The intraoperative hemorrhagic complication occurred during coiling of the aneurysm after stent placement was already performed, and aneurysm rupture was controlled by deploying additional coils. The second hemorrhagic complication occurred during follow-up, and aneurysm re-rupture $(\mathrm{SAH})$ occurred in this patient at day 30 after treatment of a ruptured pericallosal artery aneurysm. Additional coiling was performed by re-probing the aneurysm through the stent without additional complications. The complication rate was not higher in the subset of patients with small parent vessel diameters $(<1.5 \mathrm{~mm})$. Only 1 of 23 patients $(4.3 \%)$ had a complication (stent migration) in this subset.

\section{Outcome}

Immediate radiologic outcome $(n=123)$ showed RROC grades I and II in $43.9 \%$ and $39.0 \%$ of the cases, which improved at last follow-up (median, 3.6 months; $n=38$ ) to $76.3 \%$ for grade I and $13.2 \%$ for grade II, respectively (On-line Table 1 ). Clinical outcome at last follow-up was favorable with an mRS of $0-2$ in $96.9 \%$ of the patients $(n=124)$ compared with the clinical status before the procedure $(n=123,96.1 \%)$. The immediate RROC grade correlated with aneurysm location $(P<.0001)$ and rupture status during treatment $(P=.03)$ (Figure) but not with aneurysm size $(P=.25)$ or wide-neck aneurysm status (dome-to-neck ratio of $<2, P=.12$; aneurysm neck size of $>4 \mathrm{~mm}, P=.70)$.

\section{DISCUSSION}

This multicenter postmarket analysis on the clinical use of the Atlas stent for stent-assisted coiling includes a post-FDA-approval experience with this novel device in the United States. On the basis of the early experience across academic neurovascular centers in the United States, we were able to show, in 128, patients, that the device was safe and efficient as a new aneurysm treatment tool. This provides an alternative to other stents for stent-assisted coiling such as the LEO Baby (Balt Extrusion) and LVIS Jr (MicroVention). ${ }^{2,6,7}$

Recently, several other groups reported their experiences with the Atlas stent; however, our study is the largest to date with 128 in patients and aneurysms (111 unruptured and 17 ruptured). Our study population has an age distribution, female-to-male ratio, RROC I and II occlusion rate, and average number of stents per aneurysm similar to those of most other studies (On-line Table 2 and Table). The mRS at last follow-up and retreatment rate were favorable in all studies using the Atlas stent for stentassisted coiling. All studies as well as ours showed low rates of hemorrhagic complications and permanent neurologic deficits and a mortality rate of $<5 \%$. Besides the study by ten Brinck et al, ${ }^{1}$ all studies had low rates of deployment failure and thromboembolic complications and procedure-related clinical complications below 7\%. ${ }^{6,8-13}$

The advantage of the Atlas stent is its reach in parent vessels with smaller diameters; therefore, this stent widens the endovascular treatment indication to aneurysms previously not considered candidates for stent-assisted coiling. Our results of parent vessel size measurements, stent diameter, and number of stents per aneurysm are used to confirm this: The average proximal and distal vessel sizes during stent deployment were 2.75 and $2 \mathrm{~mm}$, with a range of 1.1-4.7 and $0.7-4.2 \mathrm{~mm}$, respectively, and in $68.9 \%$ of cases, the smallest available stent $(3 \mathrm{~mm})$ was used. Furthermore, in most cases (92.2\%), only 1 stent was needed to achieve a favorable stent-assisted coiling result. More than 75\% of 

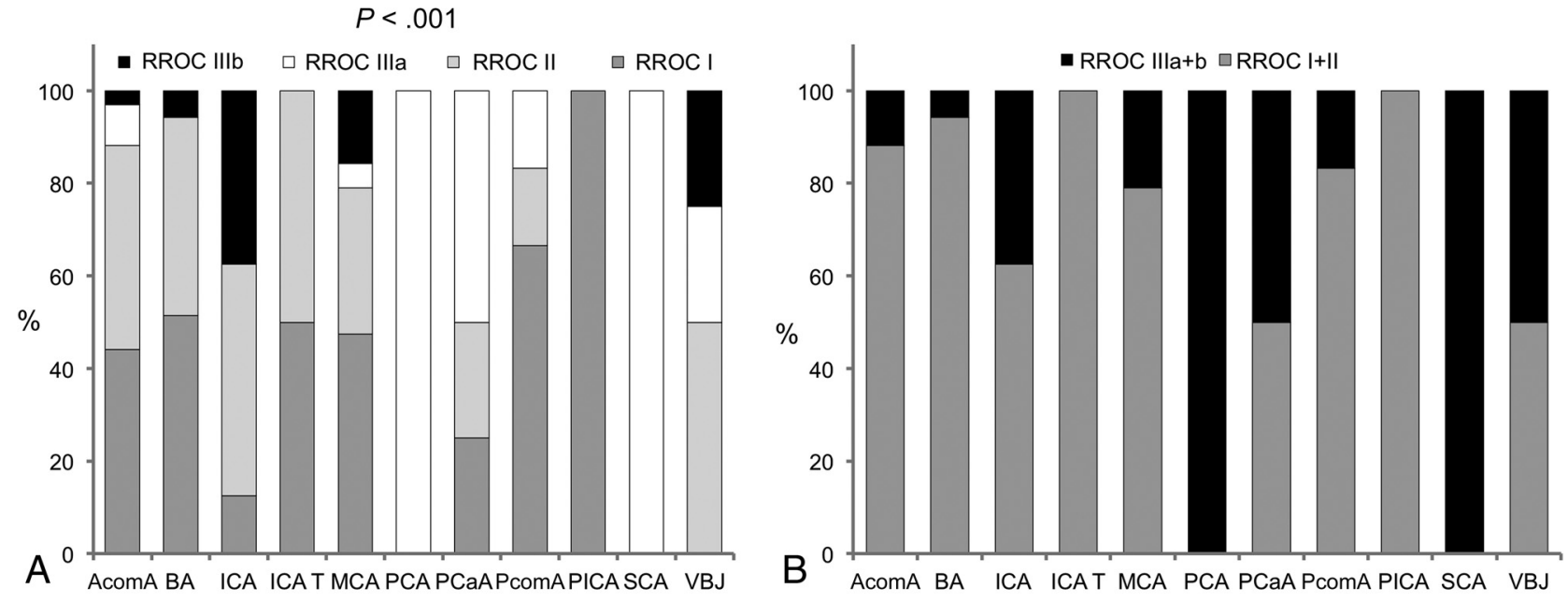

$P=.028$
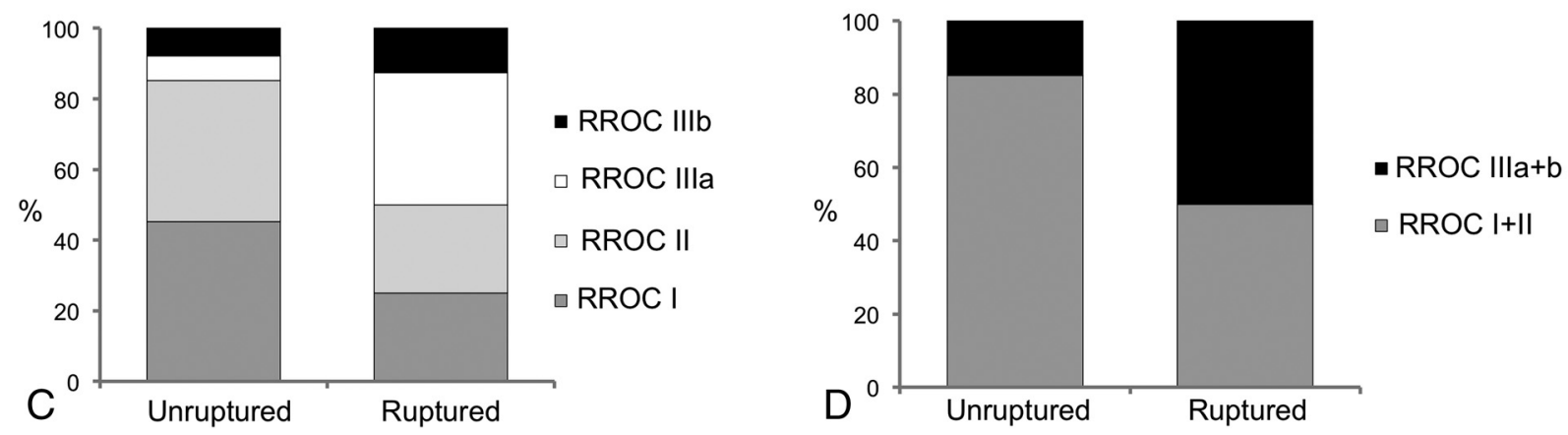

FIGURE. Immediate RROC grade (A) compared with aneurysm location and dichotomized into RROC grades I + II and IIla + IIIb (B). Immediate RROC grade $(C)$ compared with ruptured or unruptured aneurysm status before treatment and dichotomized into RROC grades I + II and IIla + IIIb (D). BA indicates basilar artery apex; ICA, supraclinoid internal carotid artery, including the ophthalmic/paraclinoid segment and anterior choroidal artery; ICA T, internal carotid artery terminus; PCA, posterior cerebral artery; PCaA, pericallosal artery; PcomA, posterior communicating artery; VBJ, vertebrobasilar junction; SCA, superior cerebellar artery.

Comparison of clinical complications with previous studies

\begin{tabular}{|c|c|c|c|c|c|c|}
\hline Study & $\begin{array}{l}\text { Deployment } \\
\text { Failure } \\
(\%)\end{array}$ & $\begin{array}{l}\text { Hemorrhagic } \\
\text { Complications } \\
(\%)\end{array}$ & $\begin{array}{c}\text { Thromboembolic } \\
\text { Complications } \\
\text { (\%) }\end{array}$ & $\begin{array}{l}\text { Procedure-Related } \\
\text { Clinical Complications } \\
(\%)\end{array}$ & $\begin{array}{c}\text { Permanent } \\
\text { Neurologic Deficit } \\
(\%)\end{array}$ & $\begin{array}{c}\text { Mortality } \\
\text { (\%) }\end{array}$ \\
\hline Caragliano et $\mathrm{al}^{8}$ (2019) & 0 & 2.65 & 3.5 & 6.2 & - & 2.65 \\
\hline Tsai et al ${ }^{12}$ (2019) & 0 & 1.7 & 5.2 & 6.9 & 0 & 0 \\
\hline Cay et $\mathrm{al}^{9}(2018)$ & 0 & 0 & 0 & 0 & 0 & 0 \\
\hline Gross et $\mathrm{al}^{6}(2019)$ & 3 & 0 & 3 & 3 & 1 & 0 \\
\hline Ulfert et $\mathrm{al}^{13}$ (2018) & 0 & 0 & 2.7 & 2.7 & 0 & 0 \\
\hline Quintana et $\mathrm{al}^{11}$ (2019) & 3.3 & 3.3 & 3.3 & 3.3 & 0 & 0 \\
\hline Jankowitz et al ${ }^{10}(2019)$ & 0 & 3.3 & 3.3 & 6.6 & 0 & 0 \\
\hline ten Brinck et al' (2019) & 11.1 & 0 & 14.8 & 18.5 & 3 & 0 \\
\hline Current study & 2.3 & 1.6 & 4.7 & 3.1 & - & 0.8 \\
\hline
\end{tabular}

Note:- - indicates not reported.

our treated aneurysms were $<7 \mathrm{~mm}$, again confirming the ability of the Atlas stent to treat smaller aneurysms in smaller parent vessels. As with other available stents for stent-assisted coiling, aneurysms treated with this technique are usually wide-neck. We found that $80.5 \%$ of patients had a wide-neck aneurysm based on a dome-to-neck ratio of $<2$, with a median dome-to-neck ratio of 1.6. Neck size $>4 \mathrm{~mm}$, another classic wide-neck aneurysm definition, was present in only $49.2 \%$ of the cases. This is not surprising because most of the aneurysms were small to begin with. Therefore, the dome-to-neck ratio is a more reliable metric to capture wide-neck aneurysms in the specific patient population with distal small wide-neck aneurysms. A subset of patients with a small parent vessel diameter $(<1.5 \mathrm{~mm})$ underwent stentassisted coiling, and we were able to show that this is feasible, with comparable results and complication rates compared with a larger $(>1.5 \mathrm{~mm})$ parent vessel size. 
Although we had only a short-term follow-up in our patient cohort, our complete aneurysm occlusion rate at last follow-up of $76.3 \%$ (RROC I) is getting close to that of surgical clipping results in classic aneurysm bifurcation locations in historical studies with comparable complication rates and outcomes. ${ }^{14,15}$ Additionally, if we counted small-neck residual occlusion results (RROC II) as favorable increases, the favorable occlusion rate would be $89.5 \%$ (RROC I and II) at last follow-up. It will be interesting to see how the RROC grade will change with time in patients with longer follow-up and whether the results of RROC grade I can then be comparable with microsurgical clipping results in the future. It was also an interesting finding that aneurysm location and ruptured aneurysm status correlated with immediate RROC grade results (Fig 1). This correlation underlines the indication of this device leading to the best angiographic results in patients with unruptured aneurysms in bifurcational locations.

The low-profile Acclino stent (Acandis; https://www.acandis. com/acclino-flex-stent-67-en) has also been reported to show results similar to those of our Atlas stent-assisted coiling study. ${ }^{16}$ However, this device is not FDA-approved, and its use in the United States is limited. The recently published study on 131 procedures with this device showed results and complication rates comparable with those in our study. ${ }^{17}$

Another advantage of the small size of the Atlas stent is that it can be deployed by the same coiling catheter, thus simplifying the coiling procedure. Because this is a new device, we still observed a high rate of using 2 separate microcatheters, one for deploying the stent and one jailed in the aneurysm to coil after stent deployment (40.6\%). In 59.4\% of the cases, the same microcatheter was used, and after stent deployment, the struts of the stent were crossed into the aneurysm for coiling. This re-probing was successful in all except of 1 case. Clearly, the advantage of jailing a second catheter is to secure the catheter position within the aneurysm, especially in challenging aneurysm neck directions off the parent vessel. On the other hand, re-probing the stent enables the coiling catheter to be free within the aneurysm and paint the only coil as with standalone coiling, along with the advantage of securing the coils within the aneurysm sac. It will be interesting to see whether the proportion of re-probing increases with time as more experience is gained with the Atlas stent.

All patients received antiplatelet medications before stent deployment, with aspirin, $325 \mathrm{mg}$, plus clopidogrel, $75 \mathrm{mg}$, daily being the most common regimen. All patients also underwent P2Y12 testing. Although unruptured aneurysms were mainly selected for the procedure, $6.3 \%$ of the patients were treated with Atlas stent coiling within 2 weeks of aneurysm rupture. Some of these aneurysms were coiled alone with only coil migration, and the Atlas stent was used as a salvage technique to reposition the coils and keep the parent vessel open. In $13.6 \%$ of patients, coils were first deployed before the stent, thus showing the ability of the Atlas stent to be used in coil migration as well as in acutely ruptured aneurysms.

There are several limitations to this study. Besides the retrospective data collection and analysis, we had only short clinical and radiologic follow-up data. Furthermore, complications and anatomic results were not independently evaluated.

\section{CONCLUSIONS}

This multicenter analysis provides a real-world safety and efficacy profile for the treatment of intracranial aneurysms with the Neuroform Atlas stent, and our excellent radiologic and clinical results are promising for future studies.

Disclosures: Jan-Karl Burkhardt—UNRELATED: Board Membership: Advisory Board, Longeviti Neuro Solutions. Visish Srinivasan-UNRELATED: Employment: Baylor College of Medicine. Andrew Ducruet-UNRELATED: Consultancy: Penumbra, Stryker, Medtronic, Cerenovus, Koswire. Bradley A. Gross-UNRELATED: Consultancy: Medtronic and MicroVention (no payment received at this point). Ajith J. ThomasUNRELATED: Consultancy: Stryker, Comments: Data Safety Monitoring Board of SCENT Trial*; Expert Testimony: CRICO, Comments: cerebrovascular cases. Georgios A. Maragkos_UNRELATED: Grants/Grants Pending: Medtronic Neurovascular Group, Comments: Neurovascular Research Fellowship Grant.* R. Webster Crowley-UNRELATED: Consultancy: Cerenovus, Medtronic, Comments: I have proctored physicians for the PulseRider device from Cerenovus and Pipeline flow-diverting stent from Medtronic. Michael R. Levitt-UNRELATED: Consultancy: Minnetronix*; Grants/Grants Pending: Stryker, Covidien, Volcano Corporation, Philips Healthcare, Comments: unrestricted educational grants*; Stock/Stock Options: eLoupes, Synchrotron, Cerebrotech Medical Systems, Comments: stock in each of these private companies. Louis J. Kim-UNRELATED: Stock/Stock Options: SPI Surgical. Justin Mascitelli_UNRELATED: Payment for Lectures Including Service on Speakers Bureaus: Penumbra, PMI.* Maxim Mokin-UNRELATED: Consultancy: Cerenovus, Canon Medical; Grants/Grants Pending: National Institutes of Health R21NS109575*; Travel/Accommodations/Meeting Expenses Unrelated to Activities Listed: Serenity Medical, Synchron, EndoStream, VICIS.* Howard Riina—UNRELATED: Consultancy: Medtronic, Stryker; Grants/Grants Pending: Medtronic, fellowship funding*; Payment for Lectures Including Service on Speakers Bureaus: Medtronic, Stryker. *Money paid to the institution.

\section{REFERENCES}

1. ten Brinck MF, de Vries J, Bartels R, et al. NeuroForm Atlas stentassisted coiling: preliminary results. Neurosurgery 2019;84:179-89 CrossRef Medline

2. Aydin K, Arat A, Sencer S, et al. Stent-assisted coiling of wide-neck intracranial aneurysms using low-profile LEO Baby stents: initial and midterm results. AJNR Am J Neuroradiol 2015;36:1934-41 CrossRef Medline

3. Sedat J, Chau Y, Gaudart J, et al. Stent-assisted coiling of intracranial aneurysms using LEO stents: long-term follow-up in 153 patients. Neuroradiology 2018;60:211-19 CrossRef Medline

4. Wang F, Chen X, Wang Y, et al. Stent-assisted coiling and balloonassisted coiling in the management of intracranial aneurysms: a systematic review and meta-analysis. J Neurol Sci 2016;364:160-66 CrossRef Medline

5. Mascitelli JR, Moyle H, Oermann EK, et al. An update to the Raymond-Roy occlusion classification of intracranial aneurysms treated with coil embolization. J NeuroIntervent Surg 2015;7:496502 CrossRef Medline

6. Gross BA, Ares WJ, Ducruet AF, et al. A clinical comparison of Atlas and LVIS Jr stent-assisted aneurysm coiling. J Neurointerv Surg 2019;11:171-74 CrossRef Medline

7. Akmangit I, Aydin K, Sencer S, et al. Dual stenting using low-profile LEO Baby stents for the endovascular management of challenging intracranial aneurysms. AJNR Am J Neuroradiol 2015;36:323-29 CrossRef Medline

8. Caragliano AA, Papa R, Pitrone A, et al. The low-profile Neuroform Atlas stent in the treatment of wide-necked intracranial aneurysms: immediate and midterm results: an Italian multicenter registry. $J$ Neuroradiol 2019 Apr 2. [Epub ahead of print] CrossRef Medline

9. Cay F, Peker A, Arat A. Stent-assisted coiling of cerebral aneurysms with the Neuroform Atlas stent. Interv Neuroradiol 2018;24:263-69 CrossRef Medline

10. Jankowitz BT, Hanel R, Jadhav AP, et al. Neuroform Atlas stent system for the treatment of intracranial aneurysm: primary results of the Atlas humanitarian device exemption cohort. J Neurointerv Surg 2019;11:801-06 CrossRef Medline

11. Quintana EM, Valdes PV, Deza EM, et al. Initial experience and one-year follow-up with Neuroform Atlas stent system for the 
treatment of brain aneurysms. Interv Neuroradiol 2019;25:521-29 CrossRef Medline

12. Tsai JP, Hardman J, Moore NZ, et al. Early post-Humanitarian Device Exemption experience with the Neuroform Atlas stent. $J$ Neurointerv Surg 2019;11:1141-44 CrossRef Medline

13. Ulfert C, Pham M, Sonnberger M, et al. The Neuroform Atlas stent to assist coil embolization of intracranial aneurysms: a multicentre experience. J Neuronterv Surg 2018;10:1192-96 CrossRef Medline

14. Mooney MA, Simon ED, Brigeman S, et al. Long-term results of middle cerebral artery aneurysm clipping in the Barrow Ruptured Aneurysm Trial. J Neurosurg 2018;130:895-901 CrossRef Medline
15. Rodríguez-Hernández A, Sughrue ME, Akhavan S, et al. Current management of middle cerebral artery aneurysms: surgical results with a "clip first" policy. Neurosurgery 2013;72:415-27 CrossRef Medline

16. Brassel F, Grieb D, Meila D, et al. Endovascular treatment of complex intracranial aneurysms using Acandis Acclino stents. $J$ Neurointerv Surg 2017;9:854-59 CrossRef Medline

17. Goertz L, Smyk MA, Siebert E, et al. Low-profile laser-cut stents for endovascular treatment of intracranial aneurysms: incidence, clinical presentation and risk factors of thromboembolic events. Clin Neuroradiol 2020 Jan 22. [Epub ahead of print] CrossRef Medline 